\title{
Research on the Path of Propaganda and Education of the Rule of Law in Colleges and Universities in New Epoch
}

\author{
Wang Jiajia ${ }^{1, a}$, Chen $Y u^{1, b}$ \\ 1Taizhou Polytechnic College, Jiangsu Taizhou, China, 225300 \\ awangjiajia_99@163.com bxiaoyueryuchen@163.com
}

Keywords: Colleges and universities, Education of the rule of law, Core value, Path.

\begin{abstract}
The rule of law is the basic content of the socialist core values. To do well in the propaganda and education of the rule of law in colleges and universities in the new era, we must take the core values of socialism into the mind and the heart as the foundation. Press closely on the word "all" to classified propulsion and give prominence to the key points, press closely on the word "deep" to strengthen leadership, improve the mechanism, press closely on the word "new" to expansion platform, innovation carrier, press closely on the word "solid" to practical use and comprehensive practice.
\end{abstract}

\section{Introduction}

In order to do a good job of propaganda and education on the rule of law, we must have clear guiding ideology, accurate work orientation and accurate advancement path, we should always closely focus on these three aspects and consistently grasp the implementation of each specific work. According to the development of macroscopic situation and the need of actual work, we should forge ahead and make bold innovations in order to ensure that all measures to popularize law are reasonable, effective and popular, and can truly take root, blossom and bear fruit, play a very good leading and promoting role.

\section{The first is the word "all", press closely on the word "all" to classified propulsion and give prominence to the key points.}

"All" is to achieve full coverage of educational objects, including the "key minority" of leading cadres at all levels in colleges and universities, the "overwhelming majority" of young college students and the "major force" of teaching staff, then extend them to society, extend to the broad masses of the people.

\subsection{Pay close attention to the key minority, cultivate the model group of respecting, studying and using the law}

General Secretary Xi Jinping has repeatedly stressed that leading cadres should be models of respecting the law and abiding by the law ${ }^{[1]}$. To carry out publicity and education on the rule of law, first of all, they should improve their literacy of the rule of law and improve the ability of deepen the reform, promote development, resolve contradictions and maintain stability by applying their thinking of rule of law. We should make full use of the theory study center group of two-level to carry out the study of education of rule of law and the theory of administering schools according to law, give full play to the role of the important organizers, promoters and practitioners of running schools according to law. Attach great importance to promoting the transformation of learning results, not only to ensure the prescribed study hours, to complete the prescribed learning content, but also to link with practice, to learn with problems, to conduct in-depth investigation and research, to study at work, and to think in the course of study, finally realize the work of learning, learning to work. 


\subsection{Strengthen the responsibility examination and strengthen the consciousness of the teaching staff to learn and use the law}

We should always take the assessment about teaching staff's study, use the rule of law and improving the enforcement of rules and regulations as an important issue, and strive to reduce and avoid the phenomenon of irregular rules and discipline. The requirement of propaganda and education of rule of law and the usage of learning law have contents and scores in the annual work goal and promotion of professional title, and they have actually achieved "year-end examination, promotion assessment". It is necessary to include the key contents of law popularization as compulsory courses in the education and training of Party League schools, compulsory courses for new teachers' pre-service training and important contents for old teachers' training, in-service training and continuing education, to stipulate minimum class hours so that teaching staff and workers will abide by the law. The consciousness of teaching according to law has been obviously improved.

\subsection{Keep a close eye on the vast majority and grasp the classroom rule of law education of young college students}

College students are the future of our country, which accounts for the "overwhelming majority" of teachers and students in colleges and universities, and is in the most plastic stage of life, which is the most important part of law popularization. Give full play to the main channels and the main position of the ideological and political theory course, actively promote the socialist core values and the contents of the education on the rule of law into the classroom, into the teaching materials, into the mind, make moral education and rule of law education work together, complement each other, promote each other and suited each other ${ }^{[2]}$ and establish the educational base for the rule of law outside the schools, and organize the practical teaching activities of the rule of law, extend the classroom to the society. In view of the actual needs of students of different majors, we should set up relevant legal courses in combination with major studies, and vigorously promotes professional legal practice, focusing on combining with students' task practice and post practice, so as to improve the understanding of the laws and regulations of the major they have learned. We should make full use of the courses of situation and policy, military theory and elective courses of public quality to meet the needs of young students for knowledge of law and to improve the legal literacy of college students.

\subsection{Deepening thematic education and improving the pertinence of publicity and education on rule of law}

According to the actual needs of college students, the special education of rule of law should be carried out pertinently. With the combination of "please come in" and "go out," we invite law experts from outside schools to be part-time vice-principals of the rule of law, constantly enrich the contents of publicity and education on the popularization of law, and conscientiously improve students' awareness of learning, understanding, and using the law. The special educational activities of rule of law have been deepened and the education of rule of law and school discipline have been listed as the important modules of freshmen's entrance education. To strengthen the effectiveness of the rule of law education, we should carry out special legal education activities, such as controlling the collection of knives and investigating the hidden dangers of public order, together with the relevant departments.

\section{The important is the word "deep", press closely on the word "deep" to strengthen leadership, improve the mechanism.}

"Deep" means that the measures are appropriate, the carriers are rich, and the means are various. They can fully mobilize the various forces, effectively integrate all kinds of resources, rapidly form a strong force, push on layer by layer, step by step, and be thorough, niceties. Carry out the work of popularizing law in a systematic and consistent manner. 


\subsection{Strengthen organizational leadership and achieve "four implementation"}

We should set up a leading group, match and strengthen full-time staff, strictly assess, and include the demands of leading cadres at all levels in the work of popularizing the law into their tenure objectives, as one of the important bases for assessing political achievements, rewards or punishments, and appointments. To establish an expert guidance mechanism for legal popularization and invite renowned legal scholars and leaders in legal practice to provide guidance. Strictly according to the standards, the funds for publicity and education on the rule of law should be included in the financial budget and increased year by year, ensure that the organization, the system, the contingent and the funds should be implemented all.

\subsection{Perfect the system and consolidate the working foundation}

We will revise, improve, and comprehensively implement all systems for leading cadres to learn and use the law, state the law at the end of the year, and further standardize the work of popularizing the law and administering schools according to law, so as to ensure the institutionalization and normalization of the work. We should pay more attention to the construction of institutions, promote the administration of schools according to law, insist on using systems to manage people's affairs and things, improve all internal management systems in a timely manner, and effectively improve the level of system building.

\subsection{Integrating the resources of all parties and deepening the linkage of departments}

We should actively integrate the resources of all parties, give full play to the advantages of all parties, establish and deepen the joint meeting system of the popularize law work, and build the work pattern of the "multisector joint popularize law", so as to form the work mechanism of the joint management and each with different areas of responsibilities. Each member unit should combine its own work, refine its work objectives and tasks, draw up a plan of activities, carry it out pragmatically, and further strengthen its joint efforts.

\subsection{Strengthen propaganda and education, create a good atmosphere}

Establish and constantly enrich the rule of law propagandists, liaison officers, instructors and university students legal aid center, weave a close network of organizations. Set up a law-popularizing voluntary service team, using one to lead a group, radiation a piece, nail down the "law-popularizing foot." Strengthen the platform carrier construction, so that a banner has a slogan, the station sign has the contents of the display, windows have plates, journals have contents, courtyard newspapers have columns, blackboards have special topics, handwritten publications have special issues, radio has programs, and there is a position on the Internet, a scrolling on the screen. To comply with the "self - media" characteristics of the whole, individuality, timeliness and cycle group. Making full use of new media such as WeChat, Weibo, micro video, micro film, mobile phone client, etc., popularizing law, strengthening the times, pertinence and effectiveness, establishing the propaganda and education system of "full coverage of public opinion and full linkage of media".

\section{The run through is the word "new", press closely on the word "new" to expansion platform, innovation carrier}

"New" is to be brave to innovate, be good at innovating, be able to combine the actual situation to innovate the train of thought, the content and the form of the rule of law propaganda and education in time, the new product frequently appears, causes the audience to like to see more, participates in it actively, unwittingly can be deeply influenced and infected.

\subsection{Strive to create a strong campus culture atmosphere of the rule of law}

It is necessary to promote the internalization of running a school according to law as a value pursuit, to guide teachers, students and staff to strengthen their civic consciousness and to strengthen their belief in the rule of law. To build a cultural square and exhibition hall for the culture of the rule of law, 
to hold various performances and exhibitions of works on the basis of the rule of law, and to make full use of the festival of science, technology, culture and art to carry out the activities of popularizing the law and construction a campus under the rule of law. Vigorously disseminate legal knowledge, carry forward the spirit of the rule of law, and foster a culture of rule of law.

\subsection{Solid development of various thematic activities on the rule of law}

Adhere to the combination of school and outside, classroom teaching and social practice, guide students to unify knowledge and practice, actively participate in the practice of the rule of law in society. To innovate ideas, bold explorate, active integrate all kinds of resources, effective promote of the rule of law propaganda and education into the countryside, into the community, into schools, to propagate legal knowledge in various forms, not only serve the masses, but also improve their own legal literacy. For example, in conjunction with traffic police and other departments to carry out civilized traffic volunteer service, in the duty process, we can active propaganda of traffic regulations, persuade people to civilized traffic, abide by the laws, cherish life.

\subsection{Constantly innovating and enriching the carrier of propaganda and education of rule of law}

Hold legal knowledge questionnaires, speech contests, combined with students' internship and employment to carry out a variety of thematic activities of rule of law education. Actively carry out the "Green Network I first" activity, correctly guide students to strengthen the awareness of the rule of law on the network, and purify the network environment with their own practical actions. Carry out the education of "negative model", compile and print the school-based teaching material of " Criminal law cases of College Students", and educate the people around them with the things around us.

\subsection{Actively expand the educational activities close to the students' reality}

Actively develop psychological counseling services, psychological crisis prevention, and promote the mental health of students. We should strengthen the education on the rule of law and the work of helping the key groups, mobilize the teaching staff, the student cadre and social forces to help the students with weak self-discipline ability and psychological distress, effectively resolve the unstable factors in the campus.

\section{The foundation is the word "solid", press closely on the word "solid" to practical use and comprehensive practice}

"Solid" is to achieve the actual effect, actual results, all kinds of legal work should be able to up to sky, down to the ground, with strong pertinence, the role is obvious, can truly promote the development of the college, and have a unique bright spot and brand work.

\subsection{Concentrate on perfect the mechanism and make decisions and management according to law}

To enrich the decision-making mechanism at the school level, to firmly promote decision-making according to law, scientific decision making and democratic decision making. We will further improve the system of president responsibility under the leadership of the party committee, the party committee system, the president's office system, and the staff congress system, amend the rules of procedure in a timely manner and strictly implement them, and promote the improvement of the awareness and accomplishment of the rule of law at all levels leading cadres. To improve the system of the joint meeting of the party and government of two stage, all major problems must be decided by the joint meeting of the party and government in accordance with the principle of democratic centralism. 


\subsection{Consciously apply the law and promote the Administration by law}

To formulate articles of association strictly in accordance with the legal procedures, to regard them as the fundamental laws of higher education, to establish all fundamental systems, and to ensure the implementation of the system, so as to promote the observance of the law and abide of the law by leading cadres and staff members at all levels, We should cultivate the habit of consciously using legal means to guide and manage the affairs of the college, conscientiously handle affairs according to the institution of the college, and strive to form a modern university system under the leadership of the Party committee, the responsibility of the president, school run by professors, and democratic supervision. To actively promote the openness of colleges' affairs, to ensure that the power runs in the sun, to promote and appoint cadres, to assess and evaluate staff and to promote their professional titles, and to ensure that the procurement of large quantities of materials and maintenance of infrastructure are conducted in accordance with procedural fairness, and openness. Take the initiative to accept staff and social supervision.

\subsection{Strengthening the construction of a clean government and perfecting the punishment and prevention system}

We should firmly promote the construction of a system of punishing and preventing corruption, and further improve the main responsibilities of party committees, the supervisory responsibilities of discipline inspection commissions, and the work mechanisms in which other units have their own responsibilities. We will thoroughly implement the responsibility system of "one post and two responsibilities" for party conduct and clean government, conscientiously strengthen leading cadres and key posts at all levels, educate and supervise key people, and continuously improve the work level of building a clean and honest party style.

\subsection{Strictly standardize the management and form a good order}

Guided by the socialist core values and in accordance with the latest laws and regulations and the school regulations of the new era, it timely combs and revises the original system, compiles the books and strictly implements the rules and regulations in the work of teaching, scientific research and management. The responsibility system of comprehensive management of campus safety, the responsibility system of fire safety management and the responsibility system of safety objective management should be signed and strictly implemented step by step, so as to ensure the transfer of responsibility and the good work order and safety order on campus.

\section{Acknowledgement}

This research was financially supported by the Special Project on ideological and political work of philosophy and Social Sciences Research in Jiangsu Province(2017SJBFDY683), and the Key projects of Scientific Research Foundation of Taizhou Vocational and Technical College(TZYKYZD-17-4), and the Funded projects of "six groups" of talents engineering training object in propaganda culture system in Taizhou City.

\section{References}

[1] Xi Jinping. Xi Jinping talks about governing[M], Volume 2: leading cadres should be models of respecting the law and abiding by the law, foreign language publishing house, 2017:126.

[2] Xi Jinping. Xi Jinping talks about governing[M], Volume 2: adhere to the combination of governing the country according to Law and running the country with morality, foreign language publishing house, 2017:133. 